\title{
Development of Self-Recognition in the Infant
}

\author{
BENNETT I. BERTENTHAL AND KURT W. FISCHER \\ University of Denver
}

\begin{abstract}
A hypothesized five-stage developmental sequence of self-recognition behaviors was tested in 48 infants between 6 and 24 months of age, and the self-recognition sequence was compared to the development of object permanence. The predicted self-recognition sequence consisted of five tasks that the infants performed in front of the mirror, with later-developing tasks requiring the coordination of a larger number of behaviors relating to the infant's mirror image than earlier-developing tasks. The development of object permanence was assessed with the Uzgiris-Hunt scale, and the object-permanence items were assigned to stages that structurally paralleled the five stages of self-recognition. The self-recognition tasks formed an almost perfect Guttman scale, with $\mathbf{4 6}$ out of $\mathbf{4 8}$ infants fitting the predicted developmental sequence precisely. This finding thus resolves most of the disagreements in previous research on the development of self-recognition: Previous studies examined different behaviors, which develop at distinct stages in the sequence. Object permanence and self-recognition showed a strong correlation, but there was no consistent relationship between the two skills across age groups.
\end{abstract}

One event of major significance in the development of the child is the emergence of a notion of self. Research on the emergence of the self has been sparse, however, probably because of the difficulty of specifying the behaviors that reflect the early development of the self. The few existing studies have usually focused on one particular situation: the reaction of an infant to his own image in a mirror. This situation appears to be ideal for assessing at least one aspect of the development of the notion of self, the development of self-recognition.

Yet the study of self-recognition has

This research was supported by a grant from the Grant Foundation and National Institute of Mental Health Predoctoral Fellowship 1 F31 MHO5280-01 to the first author and a grant from the Spencer Foundation to the second author. Portions of this article were previously presented at the 47th Annual Meeting of the Eastern Psychological Association, New York City, April 1976.

The authors wish to thank Scott Barron, Paul Corbitt, and Margot Gellman for their assistance in running infants and scoring data. Special thanks are extended to Joseph Campos for many helpful suggestions throughout the entire course of this study.

Requests for reprints should be sent to Bennett Bertenthal, Department of Psychology, University of Denver, Denver, Colorado 80208. proven to be more complex than one might expect. The research literature is full of confusions and contradictions, mostly arising from differences in the behavioral definitions of self-recognition. Infants show many different behaviors in front of a mirror, and different investigators have chosen different behaviors as indicative of true selfrecognition (Amsterdam, 1972; Boulanger-Balleyguier, 1964; Darwin, 1877; Dixon, 1957; Gallup, 1970; Stutsman, 1931; Zazzo, 1975; Brooks-Gunn \& Lewis, Note 1). Consequently, investigators have reached widely divergent conclusions about how and when self-recognition first develops.

Our thesis is that self-recognition does not emerge suddenly with one particular behavior, but develops gradually through a succession of types of behaviors, all of which relate to self-recognition. Accordingly, most of the previous contradictions appearing in the literature can be resolved by the specification of a cognitive-developmental sequence of self-recognition behaviors.

No previous research has clearly demonstrated a developmental sequence of selfrecognition behaviors (Brooks-Gunn \& Lewis, Note 1), although several inves- 
tigators have suggested that such a sequence exists (for example, Amsterdam, 1972; Dixon, 1957). The search for a developmental sequence has been stymied by both vague definitions of proposed stages and the absence of a clear rationale for predicting any specific sequence.

The present study was designed to overcome these limitations and test for a predicted cognitive-developmental sequence of self-recognition behaviors. A sequence of five steps was predicted by an a priori theoretical analysis, and five specific tasks were devised to correspond to the five steps. The theory used to predict the sequence was derived in part from Piaget's framework for describing development during infancy, which he called the sensorimotor period (Piaget, 1936/1952).

Piaget divided sensorimotor development into six sequential stages, which in theory should allow one to predict six stages of self-recognition (and likewise, six stages in the development of any task domain). But in practice Piaget's stages do not actually produce clear-cut predictions. The predominant problem with the stages is that they are never defined precisely (Uzgiris \& Hunt, 1975, p. 21).

To overcome this fuzziness, Fischer (Note 2) has proposed a theory of cognitive development that provides a more precise method of predicting developmental sequences. Piaget's six stages, as well as a number of additional sensorimotor stages, are defined in terms of the type of coordination of actions that the infant can control. In the present study, we devised one selfrecognition task to correspond to each of Fischer's definitions of Piaget's Stages 3 through 6, as well as a Stage 7 proposed by Fischer. The five tasks are described in Table 1.'

One other problem with Piaget's use of stages is that he implies that as a rule, behaviors at a given stage will develop simultaneously, even if they involve widely differing tasks and therefore widely differing skills. A number of investigators have found that many behaviors assigned to a given

1 A detailed explanation of the theoretical derivation of each task may be obtained from the authors.
Piagetian stage simply do not emerge simultaneously in a cluster (for example, Bullinger, 1973; Jackson, Campos, \& Fischer, 1978; Kopp, O'Connor, \& Finger, 1975). In view of these findings, Fischer (Note 2) has hypothesized that within a restricted task domain, a developmental sequence can be predicted, but that precise synchrony across task domains occurs only rarely. To help clarify this issue, we added a second set of tasks to our study, tasks designed to measure the development of object permanence (Piaget, 1937/1954) from Stages 3 to 7. Our prediction was that self-recognition and object permanence would show no precise synchrony, nor would one prove to be a consistent prerequisite for the other, even if they followed the predicted sequences.

To recapitulate, we hypothesized that (a) self-recognition in infants develops according to a predicted sequence of stages, and (b) even though object permanence develops according to the same sequence of stages, self-recognition and object permanence do not develop in perfect synchrony. In order to test these hypotheses, we administered a series of self-recognition tasks, as well as a series of object-permanence tasks, to a group of infants ranging in age from 6 to 24 । months.

\section{Method}

\section{Subjects}

Subjects were 48 infants ( 24 male, 24 female) divided evenly into six age groups: $6,8,10,12,18$, and 24 months. The data from 5 additional infants were discarded because the infants were uncooperative or were not living with their biological parents. All infants were selected from a larger group whose parents had volunteered to have their children participate in studies at the Cognitive Development Laboratory at the University of Denver.

\section{Procedure}

The procedures and scoring criteria for the five selfrecognition tasks are described in Table 1. According to Piaget (1937/1954), infants do not demonstrate any awareness of themselves during sensorimotor Stages 1 and 2. The simplest task in the present study was designed, therefore, to correspond to Stage 3 .

When the mother and infant arrived at the laboratory, they were directed to a waiting room, where they were greeted by the experimenter (the first author). While 
Table 1: Self-Recognition Tasks for Each Cognitive-Developmental Stage

\begin{tabular}{|c|c|c|c|}
\hline Task & Procedure & Criterion & Rationale \\
\hline $\begin{array}{l}\text { Tactual } \\
\text { explora- } \\
\text { tion }\end{array}$ & $\begin{array}{l}\text { The infant was placed in front } \\
\text { of the mirror so that he or she } \\
\text { faced the mirror }\end{array}$ & $\begin{array}{l}\text { Stage } 3 \\
\text { Within } 3 \text { minutes (Phase 2), } \\
\text { the infant had to simulta- } \\
\text { neously look at and touch some } \\
\text { part of his or her mirror } \\
\text { image. }\end{array}$ & $\begin{array}{l}\text { The infant must coordinate his } \\
\text { or her own reaching with the } \\
\text { image that he or she sees in } \\
\text { the mirror. }\end{array}$ \\
\hline $\begin{array}{l}\text { Hat } \\
\text { task }\end{array}$ & $\begin{array}{l}\text { The infant was suited in a } \\
\text { specially designed vest that } \\
\text { held a hat above his or her head } \\
\text { by means of a wooden rod } \\
\text { and wire frame attached to } \\
\text { the vest behind the infant's back. } \\
\text { Then the infant was placed } \\
\text { in front of the mirror. }\end{array}$ & $\begin{array}{l}\text { Stage } 4 \\
\text { Within } 2 \text { minutes (Phase 3), } \\
\text { the infant had to look at the } \\
\text { mirror image of the hat and } \\
\text { then immediately look up at } \\
\text { the real hat or try to grab the } \\
\text { real hat. That is, the infant } \\
\text { had to demonstrate an im- } \\
\text { mediate behavioral connection } \\
\text { between looking at the mirror } \\
\text { image of the hat and looking at } \\
\text { or grasping the real hat. }\end{array}$ & $\begin{array}{l}\text { The infant must coordinate his or } \\
\text { her own reaching with both the } \\
\text { image that he or she sees in the } \\
\text { mirror and the movements of his } \\
\text { or her own body. Because the hat } \\
\text { is directly connected to the } \\
\text { infant's body, its movements } \\
\text { are a simple extension of } \\
\text { the body movements. }\end{array}$ \\
\hline $\begin{array}{l}\text { Toy } \\
\text { task }\end{array}$ & $\begin{array}{l}\text { The infant was placed in front } \\
\text { of the mirror. When he or she } \\
\text { was facing the mirror, a toy } \\
\text { was lowered from the ceiling, } \\
\text { behind the infant, until it } \\
\text { projected an image in the } \\
\text { mirror a little above the } \\
\text { infant's eye level. }\end{array}$ & $\begin{array}{l}\text { Stage } 5 \\
\text { Within } 30 \text { sec after first } \\
\text { looking at the mirror (Phase } \\
\text { 4), the infant had to look at } \\
\text { the mirror image of the toy } \\
\text { and turn directly toward the } \\
\text { real toy. Thirty sec was } \\
\text { chosen as the time limit in } \\
\text { order to minimize ambiguous } \\
\text { cases, in which the infant } \\
\text { would turn around and locate the } \\
\text { toy without showing an } \\
\text { immediate behavioral con- } \\
\text { nection between looking at the } \\
\text { mirror image and finding the } \\
\text { toy. If the infant showed the } \\
\text { ambiguous behavior within } 30 \\
\text { sec, the task was repeated. } \\
\text { Such repetitions could occur } \\
\text { only once. }\end{array}$ & $\begin{array}{l}\text { The infant must coordinate his or } \\
\text { her body movements, which now } \\
\text { subsume reaching, with the } \\
\text { mirror images of his or her own } \\
\text { body and the toy. Unlike the hat } \\
\text { in the Stage } 4 \text { task, the toy is } \\
\text { not connected to the infant's body, } \\
\text { and its movements are there- } \\
\text { fore independent of the infant's } \\
\text { movements. }\end{array}$ \\
\hline
\end{tabular}

Rouge A dot of rouge was applied to task the tip of the infant's nose. After a free-play period, the mirror was brought into the room, and the infant was placed in front of it.

\section{Stage 6}

Within 3 minutes (Phase 2), the infant had to look in the mirror and then touch his or her nose or indicate orally that something was different about it.
The infant must coordinate his or her own body movements with the mirror image of the infant's face and with the infant's schema for what his or her face (her nose) normally looks like in a mirror.

\section{Stage 7}

Immediately following the mother's question (Phase 2), the infant had to state his or her name or use an appropriate personal pronoun.
The infant must coordinate (a) his or her own body movements with the mirror images of his or her body and the mother pointing and (b) the mother's vocalization with his or her own vocalization, and the infant must coordinate $a$ and $b$ with each other. seated in the waiting room, the mother received explicit instructions about the experiment. These instructions included detailed information about how she should administer certain tasks to her child and also descriptions of specific behaviors she should a void during the experiment, such as prompting her child. Toward the end of the orientation period, the mother was asked to apply a large dot of rouge, in as unobtrusive a fashion as possible, to the infant's nose.

Mother and infant were then brought into a small room, $2.8 \times 2.4 \mathrm{~m}$. The infant's behavior throughout the experiment was recorded on videotape from an adjoin- 
ing observation room, through a filming window that was almost completely covered with a curtain. To minimize the chances of the child becoming distracted during the experiment, the room was kept empty except for the presence of one chair for the mother.

When the mother and infant entered the experimental room, the first of five phases of the experiment was begun. The mother was present for all five phases, but after the familiarization phase she did not interact with her infant except to administer the self-recognition tasks.

Phase 1. Mother and infant remained alone in the experimental room for approximately 5 minutes, which constituted the familiarization phase. This period of time allowed the infant to become familiar with the new environment and also provided a baseline period for observation of the infant's initial reaction to his nose after the rouge had been applied. At the end of this period, the experimenter entered the room carrying a full-length mirror $(141.0 \times 39.4 \mathrm{~cm})$ supported by a wooden base $(48.3 \times 40.3 \mathrm{~cm})$. The mirror was positioned in a corner of the experimental room opposite the observation window, at $45^{\circ}$ angles to the walls. Positioning the mirror in this manner allowed us to record the infant and his mirror image simultaneously. The experimenter then left the room.

During approximately the next 10 minutes, the mother administered the five self-recognition tasks to her infant in the following three parts (Phases 2-4):

Phase 2. During this phase, the infant had an opportunity to respond to three of the self-recognition tasks: the tactual-exploration, rouge, and name tasks. The mother placed her infant in front of the mirror and moved to one side so that her image was not also projected in the mirror. Immediately after moving to this position, the mother pointed to the infant's mirror image and asked three times in succession, "Who's that?" She then encouraged the infant to play in front of the mirror. After 3 minutes had elapsed from the time the mother first approached the mirror, she was signaled that this phase had ended by the sounding of a short, low-frequency tone. (A similar signal was used to indicate the end of every subsequent phase of the session during which the experimenter was not present.)

Phase 3. This phase was designed to test the infant's performance on the hat task. First, the mother placed a specially designed vest on her infant. Attached to the vest was a wooden rod which extended over the infant's head; on top of the rod was a hat. For each infant the height of the hat was adjusted so that it always rested approximately 6 inches $(15.2 \mathrm{~cm})$ above the head. Once the vest had been fitted, the mother and infant returned to the mirror. While sitting at the side of the mirror (as in Phase 2), the mother directed the infant's attention to the mirror image of the hat and asked him or her to find the hat. This part was concluded either when the infant located the real hat or after 2 minutes had elapsed (whichever came first).

Phase 4. This phase was designed to test the infant's performance on the toy task. The toy was a small rubber doll measuring $15.2 \times 10.2 \mathrm{~cm}$ and resembling a mouse. During the previous phases of this experiment, the toy remained suspended on the ceiling, concealed by a small cardboard box (measuring $25.4 \times 20.3 \times 16.5$ $\mathrm{cm}$ ). After the mother placed her infant in front of the mirror and moved to one side, the toy was lowered until its image could be seen in the mirror, a little above the infant's eye level. If the infant did not immediately begin searching for the toy, the mother would point to the mirror image of the toy and ask the infant to bring her the toy. This phase was concluded either when the infant had located the toy or after 2 minutes had elapsed (whichever came first).

Phase 5. Immediately following Phase 4 , the experimenter entered the room again. After spending a few minutes talking to the infant, he began to administer Items 3 to 15 of the Uzgiris-Hunt scale of object permanence. Testing was concluded with the first item failed. Procedures for each task are described by Uzgiris and Hunt (1975, Chap. 11).

The order of the tasks in Phases 2 to 5 was designed to minimize interference between tasks and maximize the infants' performance. During pilot testing we found that early presentation of the hat task and especially the toy task distracted the infants and interfered with their performance on the other self-recognition tasks. Also, the object-permanence tasks were always presented last because they seemed to be more interesting to the infants than most of the mirror tasks, and therefore they helped to minimize problems with fatigue or boredom.

Scoring. Working from videotapes of each session, an undergraduate observer, unaware of the original hypotheses and the criterion behaviors for each task, recorded each infant's behaviors on a behavioral checklist. ${ }^{2}$ In accord with the criteria for each task listed in Table 1 , the behavioral checklist items indicated directly whether each task had been passed. To determine observer reliability, the first author also scored the behaviors of one infant randomly chosen from each of the 12 Age $\times$ Sex conditions. Observer agreement was found to be $99 \%$ on all tasks except the hat and rouge tasks, for which reliability was $92 \%$. Disagreements were left as originally scored by the undergraduate observer. Each infant was assigned a stage corresponding to the highest task passed. Infants who failed all the tasks were assigned to Stage 2 . The correlation between stage assignments for the two scorers was high, $r(10)=$ $.95, p<.001$.

The object-permanence items were also coded in a behavioral checklist by the undergraduate observer and then scored as passed or failed according to the scoring criteria described by Uzgiris and Hunt (1975, p. 222). Fischer's definitions of stages were used to assign the items to Stages 3 to 7 (corresponding to the stages of self-recognition). The criterial item for each stage was as follows: Stage 3, Item 3; Stage 4, Item 4; Stage 5, Item 8; Stage 6, Item 11; and Stage 7, Item 14. Stage 2 was defined as failure on all the items, but no infants failed the lowest object-permanence item.

\section{Results}

The experimental design allowed us to test, first, whether the five self-recognition

\footnotetext{
${ }^{2}$ A more detailed description of the behavioral coding system may be obtained from the authors.
} 
tasks followed the predicted developmental sequence, and second, whether selfrecognition and object permanence developed in synchrony.

\section{Sequence of Self-Recognition Tasks}

Table 2 shows that 46 of the 48 infants fit the predicted developmental sequence. These data were analyzed by two different tests of scalability to determine if they in fact demonstrated a Guttman scale. In both cases, the statistics can range from .0 to 1.0.

Both analyses showed that the data closely fit the predicted sequence. Green's (1956) index of consistency for the selfrecognition data was .90 ; Green states that any index greater than .50 indicates scalability. The second statistic, Loevinger's (1947) index of homogeneity, assesses not only the scalability of all the items in the sequence taken as a whole, but also the extent to which each separate item measures a different point along the same scale. The homogeneity of the test as a whole was .93. The homogeneities of the individual items were 1.00 for all the tasks except the toy task, which had a homogeneity of .97 , and the hat task, which had a homogeneity of .89 .

In addition to the tests of scalability, an analysis of variance was computed to test for age and sex differences in selfrecognition behavior. Each infant was assigned a score equal to the number of selfrecognition items passed. The only sig-

Table 2: Number of Infants at Each Stage of SelfRecognition Performance

\begin{tabular}{|c|c|c|c|c|c|c|}
\hline \multirow[b]{2}{*}{ Stage } & \multicolumn{5}{|c|}{ Self-recognition tasks } & \multirow[b]{2}{*}{$N$} \\
\hline & $\begin{array}{c}\text { Tactual } \\
\text { exploration }\end{array}$ & Hat & Toy & Rouge & Name & \\
\hline \multicolumn{7}{|c|}{ Predicted profiles } \\
\hline 2 & - & - & - & - & - & 2 \\
\hline 3 & + & - & - & - & - & 6 \\
\hline 4 & + & + & - & - & - & 18 \\
\hline 5 & + & + & + & - & - & 8 \\
\hline 6 & + & + & + & + & - & 4 \\
\hline 7 & + & + & + & + & + & 8 \\
\hline \multicolumn{7}{|c|}{ Other profiles } \\
\hline 5 & + & - & + & - & - & 1 \\
\hline \multirow[t]{2}{*}{6} & + & + & - & + & - & 1 \\
\hline & & & & & Total & 48 \\
\hline
\end{tabular}

Note. Correct performance is indicated by + . nificant effect was for age, $F(5,36)=36.05$, $p<.001$, which also demonstrated a significant linear trend, $F(1,36)=174.80, p<$ .001 .

We also carried out a check to be sure that the nose-touching behaviors in the rouge task were in fact a function of the task. We compared nose touching during the familiarization phase with that during the rouge task. Of the 13 infants who touched their noses during the rouge task, only 3 also touched their noses during the familiarization phase, in which the rouge was already on their noses but no mirror was present. This difference was significant by the McNemar test, $p<.01$, (Siegel, 1956). Also, note that during the rouge task, the infant had to touch the nose in conjunction with looking in the mirror, whereas during the baseline period, the infant could touch the nose at any point during the 5-minute familiarization phase.

\section{Self-Recognition and Object Permanence}

To assess the degree of synchrony between stages of self-recognition and stages of object permanence, we examined, first, the correlation between the two developmental scales, and second, differences between the mean stages on the two scales across the six age groups. The correlation between stage of self-recognition and stage of object permanence was moderately high, $r(46)=.84, p<.001$.

In the analysis of variance, age and sex were between-subjects variables, and task was a within-subjects variable. The dependent measure was stage. As shown in Figure 1, self-recognition and object permanence showed an Age $\times$ Task interaction, $F(5,36)$ $=4.59, p<.005$, as well as an age main effect, $F(5,36)=82.57, p<.001$. No other main effects or interactions were significant. Newman-Keuls post hoc tests $(p<.05)$ showed that the development of selfrecognition was significantly behind that of object permanence at 12 and 18 months and showed no significant difference at the other ages. The significant differences were produced by infants at Stages 5, 6, and 7 of object permanence. 


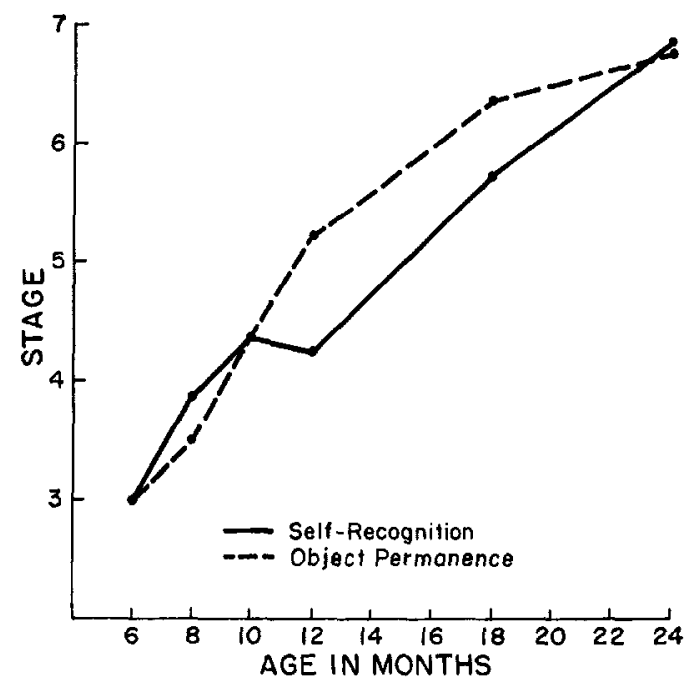

Figure 1. The relationship between self-recognition and object permanence.

\section{Discussion}

The results strongly support our analysis of the development of self-recognition but only partially support our prediction about the relationship between self-recognition and object permanence.

\section{Development of Self-Recognition}

The newly predicted developmental sequence of self-recognition behaviors was demonstrated by 46 out of 48 infants. This finding corroborates our original point about the development of self-recognition in infancy: It does not emerge suddenly at a single point in development; it develops gradually through a series of stages. This developmental sequence resolves many of the confusions and contradictions in previous research on self-recognition. The diverse behaviors investigated by different researchers can all be related to appropriate stages. For example, Dixon's (1957) criterial behavior for self-recognition was observation by the infant of his or her own movements in a mirror; this behavior first develops at Stage 3. Amsterdam's (1972) criterial behavior was detection by the infant that he or she had a red spot on the nose; this behav- ior first develops at Stage 6. Investigators need no longer argue about which behavior is true self-recognition. Instead, they can simply specify which stage or stages of selfrecognition behavior they are examining.

\section{Self-Recognition and Object Permanence}

We hypothesized that self-recognition and object permanence would not develop in perfect synchrony. Strictly speaking, the results support the hypothesis: There was no consistent relationship between self-recognition and object permanence across age groups. Sometimes the two skills were about equally advanced, and sometimes object permanence was more advanced than self-recognition. Also, the correlation between the two developmental sequences was not as high as one would have expected if they developed in perfect synchrony or if one were a prerequisite for the other.

Yet the correspondence between selfrecognition and object permanence was much higher than we had anticipated. In other research in the Cognitive Development Laboratory, the correspondence between object permanence and other sensorimotor developmental sequences has been much lower: Language use and object permanence correlated only .36 (Corrigan, 1976), and agent use and object permanence correlated .62 (Watson \& Fischer, 1977). The much higher correlation between selfrecognition and object permanence (.84) suggests that many skills may be shared by our self-recognition tasks and the objectpermanence tasks. The shared skills probably involve the ability to search for hidden objects. In the object-permanence tasks, the child tries to find objects hidden under cloths. In the self-recognition tasks for Stages 4, 5, and 6, the child tries to find objects hidden from his or her immediate view but visible in the mirror. If we had chosen self-recognition tasks that did not involve search, such as identifying things about the self in photographs or films, the correlation between self-recognition and object permanence would probably have been much lower.

What are the implications of our approach 
for studying other aspects of the development of a notion of self? Historically, many investigators have used a rather diffuse definition of self and have assumed that one measure of a notion of self, such as selfrecognition, reflects the entire category of behaviors relating to the self. We believe that the notion of self does not develop in a simple, unitary manner. The child develops many skills that relate to her or his own properties; self-recognition as we have measured it is only one of these many skills, and it probably does not develop in synchrony with all the others. We suspect that the child does not integrate these diverse skills into a true concept of self until he or she is much older than 2 years of age.

\section{REFERENCE NOTES}

1. Brooks-Gunn, J., \& Lewis, M. Mirror image stimulation and self-recognition in infancy. Paper presented at the Society for Research in Child Development Meetings, Denver, April 1975.

2. Fischer, K. W. A theory of cognitive development: The control and construction of a hierarchy of skills. Manuscript submitted for publication, 1977.

\section{REFERENCES}

Amsterdam, B. Mirror self-image reactions before age two. Developmental Psychobiology, 1972, 5, 297305.

Boulanger-Balleyguier, G. Premières réactions devant le miroir. Enfance, 1964, 1, 51-67.

Bullinger, A. Comparaison, mesure, et transitivité.
Doctoral dissertation No. 56, University of Geneva. Geneva: Éditions Médecine et Hygiène, 1973.

Corrigan, R. Patterns of individual communication and cognitive development. Unpublished doctoral dissertation, University of Denver, 1976.

Darwin, C. R. A biographical sketch of an infant. Mind, 1877, 2, 285-294.

Dixon, J. C. Development of self recognition. Journal of Genetic Psychology, 1957, 91, 251-256.

Gallup, G. G., Jr. Chimpanzees: Self-recognition. Science, $1970,167,86-87$.

Green, B. F. A method of scalogram analysis using summary statistics. Psychometrika, 1956, 21, 79-88.

Jackson, E., Campos, J. J., \& Fischer, K. W. The question of decalage between object permanence and person permanence. Developmental Psychology, $1978,14,1-10$.

Kopp, C. B., O'Connor, M. J., \& Finger, I. Task characteristics and a Stage 6 sensorimotor problem. Child Development, 1975, 46, 569-573.

Loevinger, J. A systematic approach to the construction and evaluation of tests of ability. Psychological Monographs, 1947, 6l (4, Whole No. 285).

Piaget, J. The origins of intelligence in children $(\mathrm{M}$. Cook, trans.). New York: International Universities Press, 1952. (Originally published, 1936.)

Piaget, J. The construction of reality in the child (M. Cook, trans.). New York: Basic Books, 1954. (Originally published, 1937.)

Siegel, S. Nonparametric Statistics for the behavioral sciences. New York. McGraw-Hill, 1956.

Stutsman, R. Mental measurement of preschool children. Yonkers: World Book, 1931.

Uzgiris, I. E., \& Hunt, J. McV. Assessment in infancy: Ordinal scales of psychologic development. Urbana: University of Illinois Press, 1975.

Watson, M., \& Fischer, K. W. A developmental sequence of agent use in late infancy. Child Development, $1977,48,828-836$.

Zazzo, R. Des jumeaux devant le miroir: Questions de méthode. Journal de Psychologie, 1975, 4, 389-413.

(Received February 9, 1977) 